Published in final edited form as:

Sex Transm Dis. 2005 May ; 32(5): 270-280.

\title{
Heterosexual Transmission of HIV in China:
}

\author{
A Systematic Review of Behavioral Studies in the Past Two Decades
}

HONGMEI YANG, PHD*, XIAOMING LI, PHD*, BONITA STANTON, MD*, HONGJIE LIU, PHD*, HUI LIU, MD ${ }^{\dagger}$, NING WANG, MD ${ }^{\dagger}$, XIAOYI FANG, PHD ${ }^{\ddagger}$, DANHUA LIN, PHD ${ }^{\ddagger}$, and XINGUANG CHEN, MD, PHD*

${ }^{*}$ From the Prevention Research Center the Carman and Ann Adams Department of Pediatrics, Wayne State University, Detroit, Michigan;

†From the National Center for AIDS/STD Prevention and Control, Chinese Center for Disease Control and Prevention, Beijing, China;

$\ddagger$ From the Beijing Normal University Institute of Developmental Psychology, Beijing, China

\section{Abstract}

Objective: The objective of this study was to address the role of heterosexual transmission of HIV in China.

Goal: The goal of this study was to explore the prevalence of unsafe sex and the likelihood of HIV spread heterosexually from core populations to others.

Study: The authors conducted a review of behavioral studies.

Results: Drug users were more likely to be involved in higher-risk sexual behaviors than were those who abstained from using drugs. Most female drug users (52-98\%) reported having engaged in commercial sex. Most female sex workers (FSWs) and individuals with sexually transmitted diseases (STDs) had concurrent sexual partners. Many continued to have unprotected sex after noticing STD symptoms in themselves or their sexual partners. From 5\% to 26\% of rural-to-urban migrants had multiple sexual partners and $10 \%$ of males patronized FSWs during migration.

Conclusions: Factors such as high rates of FSW patronage, low rates of condom use during commercial sex, having sex with both commercial and noncommercial sexual partners, and high rates of STD infection may promote a heterosexual epidemic in China.

After the prenatal period, transmission of HIV relies largely on unsafe sexual contact and sharing of needles for drug use, rendering its transmission to be largely restricted to certain high-risk populations. ${ }^{1}$ Except for the countries in sub-Saharan Africa, where heterosexual transmission has been identified as the initial and predominant mode of HIV transmission, in most countries, injection drug use has played an important role in the early spread of HIV. ${ }^{2}$ Subsequently, sexual transmission may play an important role in the further spread of HIV beyond injection drug users (IDUs) to other populations. ${ }^{3}$ However, the extent to which sexual transmission extends the epidemic into lower-risk population varies among countries. ${ }^{4}$ For example, in Thailand, within 8 years since 1988, four epidemic waves had been observed, beginning among IDUs, extending to commercial sex workers (CSWs), their clients, and subsequently their wives and regular sexual partners. ${ }^{5}$ By contrast, in other selected Southeast Asian countries, including China, HIV still remains low in the general population even after several years of the epidemic among IDUs. ${ }^{6}$

Correspondence: Hongmei Yang, PhD, Prevention Research Center, the Carman and Ann Adams Department of Pediatrics, Wayne State University School of Medicine, 4201 St. Antoine Street, UHC 6-D Detroit, MI 48201. E-mail: hoyan@ med.wayne.edu.. 
Data on the HIV/AIDS epidemic in China are generally gathered through a national surveillance system, which consists of case reporting, sentinel surveillance sites, and special investigations. ${ }^{6}$ Case reporting began in the mid-1980s, when sporadic HIV infections were first identified among Chinese hemophiliac patients and foreigners or overseas Chinese who were visiting China. ${ }^{7}$ Health workers at all levels of clinics, hospitals, health centers, antiepidemic stations, or various blood-testing institutes are required to report confirmed cases of HIV infection or AIDS to the local Center for Disease Control and Prevention (CDC), which in turn reports to the next higher CDC level through the system up to and including the control offices of the national CDC. In 1995, 42 national sentinel sites were established in 23 provinces under guidance from the World Health Organization. Initially, surveillance was limited to four groups: STD patients, IDUs, female sex workers (FSWs), and long-distance truck drivers. By the year 2003, the number of sentinel sites had been expanded to 194, including 72 STD patient sites from 29 of China's 31 provinces, 43 sex worker sites from 25 provinces, 49 drug-user sites from 21 provinces, 11 long-distance truck driver sites from 10 provinces, 18 antenatal women sites in eight provinces, and one site for men who have sex with men. 8

Surveillance data indicate that the HIV/AIDS epidemic in China has progressed through the entry and localized spread phases, and has reached the rapid spread phase. ${ }^{9}$ HIV has spread beyond Yunnan province, the initial localization of the epidemic. During 1995-1997, more than $50 \%$ of new HIV infections in China were among IDUs outside Yunnan. ${ }^{10}$ By 1998 , HIV infection had been reported from all 31 Chinese administrative regions (i.e., provinces, autonomous regions, and municipalities). As of the end of 2003, 62,159 infections had been documented with 840,000 estimated HIV infection cases nationwide (range,

$650,000-1,020,000) .{ }^{11}$ The ratio of male to female cases was $1.8: 1$. Most cases $(64.7 \%)$ were among individuals 20 to 39 years of age, of whom $51.2 \%$ were infected through injection drug use, $21 \%$ through blood/plasma collection or infected blood transfusion procedures, $7.5 \%$ through sexual contact (hetero- or homosexual), and $0.4 \%$ through vertical transmission. The source of infection was unknown for $18.1 \%$ of the infected. ${ }^{11}$

With a population of 1.3 billion, China has a relatively low HIV infection rate $(<0.1 \%$ among adults). However, the HIV prevalence rate exceeds 5\% among IDUs in Yunnan, Xinjiang, Guangxi, Guangdong, Sichuan, Guizhou, Hunan, Jiangxi, and Beijing. ${ }^{6}$ Likewise, the HIV prevalence rate among blood/plasma donors in Henan, Anhui, Shanxi, Shaanxi, Hubei, Hebei, Shandong, and Guizhou provinces has reached an average of $10 \%$ to $20 \%$, with rates as high as $60 \%$ in some communities. ${ }^{6,12}$ The recent increase in the number of STD cases and sexually transmitted HIV infections suggests that sexual transmission may serve as a bridge connecting core populations with other populations. ${ }^{6,13}$ Given the overall low HIV infection rate nationwide, but the high prevalence in core populations in particular regions, and the existence of potential "bridge" populations, efforts targeting these critical populations are of urgent need. In the current study, we comprehensively review the scientific literature on HIV epidemic in China, and seek to 1) explore the epidemic of unprotected heterosexual sex among various subpopulations, and 2) examine the likelihood of HIV spread from core populations to the general population by analyzing the extent of sexual contact among different subpopulations.

\section{Materials and Methods}

Several methods were used for assessing the relevant literature. First, MEDLINE was searched for articles, editorials, and letters published in peer-reviewed journals from 1985 through May 2004. Second, the China Periodicals Database, one of the most comprehensive Chinese scientific literature databases, was searched for available Chinese articles published in major peer-reviewed journals relevant to HIV/AIDS, including the Chinese Journal of Prevention and Control of STD and AIDS (1997-2003), the Chinese Journal of Epidemiology (1998-2003), the Chinese Journal of Public Health (2001-2003), and the Chinese Journal of Preventive 
Medicine (1998-2003). Third, we examined the reference sections of reviewed articles to identify additional articles. Finally, official reports and workpapers on HIV/AIDS from UNAIDS/WHO or the China Ministry of Health were identified and reviewed.

Key words, alone or in combinations, used for the searches included China, HIV, AIDS, STD, sexual behavior, and drug use. Studies among different populations in Hong Kong were not included in this article because the healthcare system in Hong Kong is significantly different from those throughout the rest of China. Studies among men who have sex with men were also not included because we believed that the scope and significance of the issue deserve a separate review.

The literature review examined several groups playing putatively important roles in the epidemic: drug users, former blood/plasma donors, FSWs, attendees at STD clinics, rural-tourban migrants, and the general population. IDUs and former blood/plasma donors appear to be two core HIV-infected populations in China. Whether and how HIV can be transmitted from core populations to the general population depends on sexual contacts among these and other groups. We reviewed behavioral studies conducted among these groups and present summaries of their HIV-related sexual behaviors, including number of sexual partners, type of sexual partners, and condom use. To have a comprehensive picture about the situation of HIV in China, we first briefly introduce each subpopulation and their HIV infection situation followed by a discussion of their HIV-related behaviors.

\section{Results \\ Drug Users}

Since the mid-1980s when Yunnan province became a principal trafficking route for illegal drugs entering China, illegal drug use has spread to involve much of China. Among China's 2143 counties, 2033 have reported drug use and 140 counties have more than 1000 registered drug users. ${ }^{14}$ Most registered drug users are men and under the age of 30 years. ${ }^{14}$ Risk drugtaking behaviors are prevalent among drug users. The progression time from smoking to injection appears to be shortening, particular among younger drug users. ${ }^{15}$ The proportion of IDUs among illegal drug users nationwide was $13.5 \%$ in $1988,1642 \%$ in 1994 , and $50 \%$ to $60 \%$ during 2000 to $2003 .{ }^{8}$ There is substantial geographic variation in injection drug use, with the level approaching $80 \%$ to $90 \%$ in Yunnan and Guangxi. ${ }^{14}$ Shared use of injection equipment is common among IDUs, with sentinel surveillance data indicating that in 2003, more than $40 \%$ of IDUs shared injection equipment. ${ }^{8}$

The HIV infection rate among drug users reached $7.23 \%$ in $2003 .{ }^{8}$ In some regions, including Yunnan and Guangxi, the infection rate was as high as $70 \%$ to $80 \%$ among IDUs. ${ }^{17}, 18$ Yunnan was the first province in China affected by an HIV epidemic among IDUs dating back to 1989. Since then, serious epidemics among IDUs have been identified in Xinjiang (1996), Guangxi and Sichuan (1997), Guangdong (1998), Gansu (1999), and Jiangxi (2000). ${ }^{14}$

A summary of studies among drug users describing their sexual behaviors or STD histories is presented in Table 1. ${ }^{7,16,18-25}$ The majority of drug users were sexually experienced, whereas only one third were married. Approximately $30 \%$ to $75 \%$ reported having had multiple sexual partners whether or not they had a primary partner. Condom use rate was low, with reported rates of "always use" ranging from $0 \%$ to $28 \%$. Many drug users reported never having used a condom during sex (range, 32-100\%). A study in Yunnan and Guangxi in 1996 reported a $7 \%$ STD prevalence rate, ${ }^{19}$ and a study in Pingxiang, Guangxi, in 1998 found a $17 \%$ rate. $^{21}$

Wu and colleagues found that among 1548 males aged 18 to 29 years old from 82 villages in Longchuan, Yunnan province, 433 were identified as drug users. Compared with nondrug- 
using villagers, drug users were more likely to have had premarital sex (odds ratio [OR], 3.3; 95\% confidence interval [CI], 2.3-4.5) or extramarital sex (OR, 5.4; 95\% CI, 2.7-10.9) in the previous year. $^{26}$ Drug users were also 2.3 times more likely to have had at least four sexual partners in the past year than nondrug users $(P<0.001) .{ }^{26}$ Another study reported a positive relationship between risky drug-taking behaviors and risky sexual behaviors. Drug users injecting drugs and sharing needles, compared with IDUs who did not share needles or nonIDUs, had significantly higher rates of having multiple sexual partners $(73 \%, 60 \%$, and $54 \%$, respectively, $P<0.001)$ and never having used a condom $(71 \%, 62 \%$, and $56 \%$, respectively, $P<0.01) .{ }^{19}$

High HIV infection rates were observed among spouses in areas where the HIV infection rate was high among drug users. A 1992 survey in three cities of Yunnan reported that six (10\%) of the 61 wives of HIV-infected IDUs tested HIV-positive. None of the wives reported using drugs themselves or using condoms. ${ }^{16}$ Another study in Ruili among discordant couples found that among 128 spouses of HIV-infected IDUs, 16 (12.5\%) were HIV-positive. None of the infected spouses were drug users or sexually promiscuous, and none of them had used condoms while having sex with their spouse. ${ }^{27}$ The HIV prevalence increased from $3.1 \%$ in 1990 to $12.3 \%$ in 1997 among spouses of HIV-infected IDUs in Yunnan province. ${ }^{28}$

The population of female drug users appears in recent years to be increasing and becoming younger. In Yunnan and Guangxi, females constitute $16 \%$ to $25 \%$ of all drug users in detoxification centers. ${ }^{14}$ In Guangxi, the average age of female drug users was 20 to 23 in the mid-1990s, whereas in 2001, the average age was 17 to 18 years. ${ }^{14}$ Female drug users who started using drug at a younger age are more likely than those who started at an older age to have multiple sexual partners. ${ }^{19}$ Three studies among female drug users found that most of them (52-98\%) reported having exchanged sex for money or drugs. Some used drugs first followed by prostitution, whereas others initiated prostitution before drug use. ${ }^{24}$ The study in Gansu found that the percentages of drug users who had multiple sexual partners or were involved in extramarital sex were significantly higher for drug users who sold sex (71.6\% and $72.2 \%$, respectively) compared with those who reported no involvement in commercial sex (39\% and $30.6 \%$, respectively). The study also found that drug users who sold sex were more likely than those who did not sell sex to use intravenous drugs $(47.2 \%$ vs. $17.9 \%, P<0.01)$ and to share needles $(45 \%$ vs. $7.1 \%, P<0.05){ }^{22}$

\section{Blood/Plasma Donors}

In the early 1990s, thousands of underground for-profit blood/plasma collection centers were established in China, especially in rural areas. Paid blood collection, especially plasma collection, attracted numerous low-income peasants or rural residents. ${ }^{12}$ The majority of paid donors were adults aged 20 to 50 years. ${ }^{12}$ In these illegal blood/plasma collection center, unsterilized blood-collecting equipment was often reused and pooled blood cells were reinjected back to plasma donors after filtering the plasma. ${ }^{29,30}$ These blood/plasma collection practices placed blood donors at risk for contracting HIV infection. Since the mid-1990s, a large number of HIV infections have been reported among blood donors in many provinces, especially in central China. ${ }^{6}$ According to epidemiologic investigations, the HIV prevalence rate among blood donors in Henan, Anhui, Shanxi, Shaanxi, Hubei, Hebei, Shandong, and Guizhou provinces has reached an average of $10 \%$ to $20 \%$, with certain communities having rates as high as $60 \%{ }^{6}$ Subsequently, the Chinese government has instituted several measures to prevent further spread of HIV through blood collection, including outlawing all unlicensed blood collection centers and enforcing HIV testing for all blood donors. 31

It is believed that most infections of donors occurred before 1996. However, unsafe bloodcollecting practices continue in some areas because illegal centers persist, ${ }^{32}$ and some licensed blood collection centers do not adhere strictly to relevant governmental regulations. ${ }^{33}$ 
To date, there have been virtually no studies focusing on former blood/plasma donors' risky sexual behaviors. One prevalence study among former commercial plasma donors in rural eastern China reported that $6 \%$ of donors had multiple sexual partners over their lifetimes. No condom use information was available. The HIV seroprevalence was $2.1 \%$ among their nondonating spouses, ${ }^{12}$ which was considerably higher than reported among other risk groups and the general population at that time (in 1997). ${ }^{12}$

\section{Female Sex Workers}

Since the early 1980s when commercial sex reemerged in main-land China after two decades of virtual extinction, prostitution has developed into a widespread industry. ${ }^{34}$ In 2003 , the number of women engaging in commercial sex in mainland China was estimated to exceed 10 million. ${ }^{35}$ Most FSWs were young, in their teens or early 20s, with only a primary or junior high school education. ${ }^{36-39}$ FSWs encounter their clients in various service sectors or entertainment establishments such as restaurants, barber shops, massage and sauna parlors, bars, hotels, guest houses, and bus stations, or solicit their clients on streets or in parks. ${ }^{36}$, 38,40 Most of the FSWs are highly mobile, moving from one establishment to another approximately every 3 to 4 months 39 and/or frequently moving between cities. ${ }^{34}$

Data from sentinel sites indicated an average HIV infection rate of $0.88 \%$ among FSWs. ${ }^{8}$ Sentinel sites with FSWs who used drugs had higher HIV rates than those sites with only nondrug-using FSWs. Likewise, the HIV infection rates among nondrug-using FSWs in regions where drug use is a big problem were elevated and observed to be much higher than the national average. 8

A summary of studies on drug use and sexual behavior among FSWs is presented in Table $2 .{ }^{24,36,38-44}$ Among those studies reporting drug use behaviors, $5 \%$ to $15 \%$ of interviewees were drug users. A majority of them not only had commercial sex partners but also had one or more noncommercial steady or casual sexual partners at the same time. Their clients included a range of professions such as businessmen, officials, workers, students, and overseas foreigners. More than half of the sex workers reported never having used a condom when having sex with their main partner (spouse/boyfriend/fiancee) or casual acquaintance. Only approximately $10 \%$ reported always using condoms with sexual partners in a relationship. The consistent condom use rate was relatively higher when they had sex with clients than with stable partners, ranging from $6 \%$ in Jinan to $68.5 \%$ in Shenzhen. A substantial proportion of them reported having never used a condom with clients. One study also reported that more than half of FSWs would still have sex with a client who was perceived to be infected with an STD. A recent report indicates that the median syphilis infection rate among FSWs under sentinel surveillance was $3.4 \%$ (range, $0-33 \%$ ). ${ }^{8}$

\section{Patients With Sexually Transmitted Diseases}

The number of STD cases has risen exponentially since the initiation of economic reforms. Recently, reported STD cases ranked third among notifiable infectious diseases in China, with a total of 730,450 identified in $2003 .{ }^{45}$ The majority of the reported cases (80-85\%) were among persons 20 to 39 years of age and were married. ${ }^{46}$

In 2003, 37,619 attendees at STD sentinel clinics were tested for HIV, among whom 92 were seropositive, resulting in an average infection rate of $0.24 \%$. A few sentinel sites, which were along drug-trafficking routes, detected an HIV infection rate above $1 \%$. Twenty-four of 29 provinces with national sentinel sites reported HIV infection among STD cases. ${ }^{8}$

A study using a hospital-based random sample of patients from public STD clinics in Jinan, Shandong province, found that most STD-infected individuals reported having had multiple 
sexual partners during the prior year, with a mean number of sexual partners of 6.2 for men and 7.2 for women. Approximately $70 \%$ of males reported paying for sex, whereas one fourth of women reported being involved in commercial sex. None of the 150 female patients reported always using condoms when having sex with different types of partners. The majority of male patients never used a condom during sex. ${ }^{47,48}$ Another study conducted among 1371 STD clinic patients from 16 different provinces in 1997 indicated that $50 \%$ of males and $42 \%$ of females had casual sexual partners (i.e., classmate, coworker, or acquaintance) during the previous year. Sixty-five percent of the men and $16 \%$ of the women also had sex with attendants at hotels, karaoke bars, coffee shops, or massage parlors, street prostitutes, or hairdressers. During the same period, $78 \%$ of men and $44 \%$ of women had both steady and nonsteady partners; $59 \%$ of men and $15 \%$ of women had both noncommercial sex partners and commercial sex partners. One percent of men and $7 \%$ of women always used condoms with these partners. 49 Liu and colleagues studied sexual activities among patients with STDs in the interval between noticing symptoms and presenting for treatment. ${ }^{50,51}$ Among 406 male patients interviewed, 164 (40\%) men reported having sex after having STD symptoms. Forty-one percent had sex with their wives/fiancees, $16 \%$ had sex with both their wives and noncommercial partners, 9\% had sex with both their wives and commercial partners, 29\% had sex with both noncommercial and commercial partners, and $4 \%$ had sex with all three types of sex partners. However, only $10 \%$ of patients who had sex after noticing STD-related symptoms reported frequently or always using condoms, and approximately $60 \%$ had never used a condom. A summary of studies targeting patients with STDs is presented in Table 3.

\section{Rural-to-Urban Migrants}

The majority of China's 121 million migrants are rural-to-urban temporary economic migrants. 52 According to official registered migration data, $60 \%$ were male, $40 \%$ were aged 20 to 24 years, 53,54 and $40 \%$ had no more than a primary school education. ${ }^{52}$ Most of the migrants were unmarried or married but living apart from their spouses and/or children. ${ }^{55}$ Economically developed large cities or coastal cities/provinces had an infloating population from throughout the country. In less developed and smaller-sized cities, the infloating populations were primarily from local or neighboring provinces. ${ }^{53,56}$ Nationwide, most male and female migrants worked in industrial or service sectors. 57

It has been reported in a cross-sectional survey that the HIV prevalence among rural-to-urban migrants was 1.8 times higher ( $15.6 \%$ vs. $8.8 \%$ ) than among rural residents who did not migrate to cities. ${ }^{58}$ Among 5892 returning hometown rural residents who worked on construction sites when they were in urban areas, the STD infection rate was $4.3 \%$, which was higher than the reported STD infection rate $(28.8$ per 100,000) in the same city and the same time period. Female workers had a significantly higher STD infection rate (14.1\%) than their male counterparts (4.2\%). The infection rate among young adults aged 18 to 30 years was $8.7 \%$, compared with $2.7 \%$ for those 31 to 45 years of age and $1.5 \%$ for those 46 to 60 years old. ${ }^{59}$ Similar results were observed in another study among a sample of 983 temporary migrants in urban areas. 60

A limited number of studies among temporary migrants who are not registered in the cities to which they have migrated reported their HIV-related behaviors (Table 4). ${ }^{61-63}$ The percentage of migrants having multiple sexual partners during migration or during the last year ranged from $5.1 \%$ to $26 \%$. Approximately one tenth of males patronized FSWs, and $6 \%$ of male and female migrants had exchanged sex for money. ${ }^{61}$ Approximately $10 \%$ reported always using condoms when having sex, whereas nearly $40 \%$ never using a condom. A study among intransit people in Beijing, and restaurant workers, street peddlers, and job-seekers in Shanghai in 1999 found that $6 \%$ of migrants had sold blood during migration and $4.4 \%$ had used drugs during migration. The proportions reached $12 \%$ and $9.2 \%$, respectively, among job seekers. ${ }^{62}$ 


\section{General Population}

Several studies related to sexual behaviors have been conducted in different regions among the general population in China since the mid-1990s, including two studies among villagers in southwest and central China, one among urban residents in southwest China, and two multicity studies. $^{26,64-67}$ The main results of these studies are summarized in Table 5. Although the percentage of risky sexual behaviors varied by population, a considerable proportion of adults overall engaged in risky sexual behaviors such as having casual sexual partners and having premarital sex. All the studies reported a low percentage of condom use. The national stratified probability sample reported $10 \%$ of adult males and $4 \%$ of adult females engaged in sex with more than two noncommercial sex partners during the prior year, and $9 \%$ of men purchased sex. Only $0.3 \%$ always used condoms when engaged in sex with prostitutes. 66

\section{Discussion}

Although injection drug use and unsafe blood collection procedures remain the principle modes of HIV transmission in China, heterosexual transmission is emerging as an important contributor to the expansion of the epidemic. Risk factors that contributed to the explosive heterosexual epidemics in Thailand and Cambodia currently exist in China, including high rates of sex worker patronage, low rates of condom use during commercial sex, and concurrent sex with both FSWs and noncommercial casual or steady sex partners. ${ }^{68}$ The increasing overlap between female drug users and female sex workers, increasing rates of STDs and HIV among high-risk populations, and the growing "bridge" populations between high-risk populations and the general population may promote a rapid and extensive heterosexual epidemic of HIV in China.

The findings from this study have suggested that the current reported proportion of sexual transmission of HIV in China might be underestimated. Among the 62,159 HIV infections documented through 2003 , only $7.5 \%$ were reported to be infected through sexual intercourse (including hetero- and homosexual). ${ }^{11}$ Recent local data have suggested a much higher proportion. For example, among 316 HIV/AIDS cases reported in 2003 in Beijing, 47 were infected through heterosexual (including two bisexual) transmission (14.9\%). Likewise, among HIV/AIDS cases reported in 2003 in Jiangsu and Zhejiang, the two most populous Chinese costal provinces, the proportions of heterosexual transmission were $25.31 \%$ (41 of 162 ) and 21.8\% (34 of 156), respectively. Based on 2003 national epidemiologic data in China, Lu and colleagues estimated that among the estimated 840,000 infections, $19.8 \%$ were infected through heterosexual transmission and an additional $11.14 \%$ through homosexual transmission. ${ }^{11}$ There are a couple of possible reasons for the underestimation in overall proportion. First, the overall proportion reported was based on historical data, which do not reflect the rapid increase of sexual transmission in recent years. Second, there might be some misclassification of transmission modes because of the higher priority of IDU and former blood/plasma donors in the current surveillance system. An HIV-infected person typically is classified as being infected through sexual intercourse only when he or she has no history of using drugs or unsafe blood/plasma donation, otherwise he or she will be classified as being infected through drug use or blood/plasma donation even though he or she might be actually infected through unprotected sexual encounters.

The existing published studies on sexual behavior among high-risk and bridge populations provide valuable information assessing heterosexual transmission of HIV in China. However, there are some limitations to the available data. First, most of the measurements were based on lifetime experience rather than recent sexual practice and thus may not be reflective of sexual practice after using drugs or being HIV-infected. Second, many of the previous studies did not collect information on the types of sexual partners and/or frequency of concurrent sexual partnerships. Third, behavioral information was based on self-report and may be subject to 
underreporting. Finally, most studies of persons with STDs were conducted at public STD clinics and thus data may not be reflective of persons not attending public STD clinics.

Success in reversing the heterosexual epidemics in Thailand and Cambodia suggests that efforts targeting critical populations can alter the course of epidemics. In Thailand, CSWs and their clients served as bridge populations, assuming important roles in the HIV epidemic. In Cambodia, the HIV prevalence reached $28.8 \%$ among CSWs and $2.8 \%$ among pregnant women attending antenatal clinics in $2002 .{ }^{69}$ As soon as HIV epidemics emerged, national policymakers in both countries responded actively and took a series of prevention efforts. In Thailand, the HIV/AIDS control program became a national agenda in 1990. In 1991, the MultiSector AIDS Prevention Strategy was developed to coordinate efforts from all sectors such as nongovernment organizations, civil society, and other sectors in policy formulation. In Cambodia, the National AIDS Committee was established in 1993 to develop and implement preventive measures. The Ministry of Health made a strong political commitment to the prevention of HIV/AIDS and established the National AIDS Program, which was responsible for implementing HIV/AIDS prevention and care. Three consecutive HIV/AIDS national strategic plans were developed to guide the focus of interventions for different stages of the epidemic. In both countries, the government responded with strong national strategic plans targeting prevention. The focus of the interventions was to reduce heterosexual transmission related to sex work, and the $100 \%$ Condom Use Program was implemented. The program targeted not only CSWs, but also the establishment owners, and had the establishment owners responsible for $100 \%$ condom use by clients in their establishments. ${ }^{70}$ Establishments were monitored, penalized, and shut down for failure to comply with the program. After implementation of the $100 \%$ Condom Use Program, consistent condom use increased dramatically among CSWs and their clients, and declines of STDs and HIV incidence and prevalence were observed in both Thailand and Cambodia. 69

The HIV epidemic in China is accelerating. Fortunately, the Chinese national government has recently recognized the magnitude of the epidemic and has taken many positive actions, such as the formation of a high-level HIV/AIDS Coordinating Committee, and issuing China's Medium- and Long-Term Program (1998-2010) and the Five-Year Plan of Action (2001-2005). 6 With the supportive political environment, extensive and intensive prevention activities are needed for reducing the transmission of HIV from core populations to other populations. The low prevalence of consistent condom use and the high prevalence of failure to use a condom during commercial sex highlight the importance of condom promotion. Because most commercial exchange of sex appears to be occurring in entertainment establishments, owners of these establishments should be targeted for efficient condom promotion among FSWs.

Measures should include monitoring and establishment of "zero tolerance" procedures for failure to use condoms. Prevention efforts among rural-to-urban temporary economic migrants should use the existing kinship ties, native-place networks, and/or their workplaces to deliver HIV-related health information and protective skills. Prevention efforts should also be conducted in rural sites of origin given that the potentially infected migrants will return to these areas. To date, most HIV infections and AIDS cases have occurred in rural areas where healthcare facilities and manpower are especially inadequate. HIV prevention and control efforts in rural areas should be developed around the existing primary healthcare system, which includes the county hospitals, township health centers, and village doctors. Because most health workers at the basic level do not receive much formal medical education, HIV professional training among these health workers is urgently needed. Special funds need to be allocated for training. Given the underdevelopment of mass media systems in many rural areas, existing forms of public dissemination such as broadcasting, blackboard, and monthly or yearly village meetings should be used for disseminating HIV-related knowledge, policies and supportive information. Finally, free or affordable condoms need to be delivered to discordant couples with appropriate skill training of their use. 


\section{References}

1. Rothenberg RB, Potterat JJ, Woodhouse DE, et al. Social network dynamics and HIV transmission. AIDS 1998;12:1529-1536. [PubMed: 9727575]

2. Yu ES, Xie Q, Zhang K, et al. HIV infection and AIDS in China, 1985 through 1994. Am J Public Health 1996;86:1116-1122. [PubMed: 8712271]

3. Yu XF, Wang X, Mao P, et al. Characterization of HIV type 1 heterosexual transmission in Yunnan, China. AIDS Res Hum Retroviruses 2003;19:1051-1055. [PubMed: 14686326]

4. Weniger B, Takebe Y, Ou CY, et al. The molecular epidemiology of HIV in Asia. AIDS 1994;8(suppl 2):S13-S28. [PubMed: 7857556]

5. Weniger BG, Limpakarnjanarat K, Ungchusak K, et al. The epidemiology of HIV infection and AIDS in Thailand. AIDS 1991;5:S71-S85. [PubMed: 1845063]

6. Moh, UC., editor. A Joint Assessment of HIV/AIDS Prevention, Treatment and Care in China. UNAIDS; Beijing: 2003.

7. Xia M, Kreiss JK, Holmes KK. Risk factors for HIV infection among drug users in Yunnan province, China: Association with intravenous drug use and protective effect of boiling reusable needles and syringes. AIDS 1994;8:1701-1706. [PubMed: 7888119]

8. China, CDC. National HIV/AIDS Sentinel Surveillance Report in 2003. China CDC \& National Sentinel Surveillance Group; Beijing: 2004a.

9. Grusky O, Liu H, Johnston M. HIV/AIDS in China: 1999-2001. AIDS and Behavior 2002;6:381-393.

10. Chinese MOH and UNAIDS. Special Report, 'China Responds to AIDS.'. Chinese Ministry of Health; Beijing: 1997.

11. Lu, F.; Zhang, D.; Tian, F., et al. Preliminary Analysis of HIV Epidemic in China. National Center for Disease Control and Prevention; Beijing: 2004.

12. Wu Z, Rou K, Detels R. Prevalence of HIV infection among former commercial plasma donors in rural eastern China. Health Policy Plan 2001;16:41-46. [PubMed: 11238429]

13. Chen XS, Gong XD, Liang GJ, et al. Epidemiologic trends of sexually transmitted diseases in China. Sex Transm Dis 2000;27:138-142. [PubMed: 10726645]

14. Reid, G.; Costigan, G., editors. Revisiting 'The Hidden Epidemic'-A Situation Assessment of Drug Use in Asia in the Context of HIV/AIDS. The Centre for Harm Reduction, The Burnet Institute; Australia: 2002. p. 46-59.

15. Lai S, Chen J, Celentano D, et al. Adoption of injection practices in heroin users in Guangxi province, China. J Psychoactive Drugs 2000;32:285-292. [PubMed: 11061679]

16. Zheng X, Tian C, Choi KH, et al. Injecting drug use and HIV infection in southwest China. AIDS 1994;8:1141-1147. [PubMed: 7986413]

17. Zhang C, Yang R, Xia X, et al. High prevalence of HIV-1 and hepatitis C virus coinfection among injection drug users in the southeastern region of Yunnan, China. J Acquir Immun Defic Syndr 2002;29:191-196.

18. Yu XF, Chen J, Shao Y, et al. Emerging HIV infections with distinct subtypes of HIV-1 infection among injection drug users from geographically separate locations in Guangxi province, China. J Acquir Immun Defic Syndr 1999;22:180-188.

19. Li X, Stanton B, Zhou Y. Injection drug use and unprotected sex among institutionalized drug users in China. Journal of Drug Issues 2000:663-674.

20. Chen X, He J, Wu Y. Survey for HIV prevalence and risk factors among drug users in Hunan. Chin J STD/AIDS Prev Cont 2000;6:141-142.

21. Lai S, Liu W, Chen J, et al. Changes in HIV-1 incidence in heroin users in Guangxi province, China. J Acquir Immun Defic Syndr 2001;26:365-370.

22. Wang Q, Lin G. Sex exchange and HIV-related risk behaviors among female heroin users in China. Journal of Drug Issues 2003:119-132.

23. Lin P, Li Y, Wang Y, et al. A pilot study of the risk behaviors, HIV/AIDS knowledge and health intervention among drug users. Chin J STD/AIDS Prev Cont 2002;8:24-27.

24. Pei D, Yang B, Lai S, et al. High risk behavior investigation and syphilis infection surveillance among female sex workers and drug users in Hainan. Chin J STD/AIDS Prev Cont 2002;8:160-161. 
25. He Y, Ruan Y, Teng T, et al. Community-based survey of drug use and sexual behavior among female injection drug users. Chin J STD/AIDS Prev Cont 2003;9:343-345.

26. Wu Z, Zhang J, Detels R, et al. Characteristics of risk-taking behaviors, HIV and AIDS knowledge, and risk perception among young males in southwest China. AIDS Educ Prev 1997;9:147-160. [PubMed: 9167800]

27. Yang Z, Duan Y, Li Z, et al. HIV transmission among spouses of IDUs in Ruili, Yunnan province. Chin J STD/AIDS Prev Cont 1997;3:247-250.

28. Zheng, X.; Zhang, J.; Qu, S., et al. A cohort study of HIV infection among IDUs and natural history of HIV infection in Ruili, China, 1992-1997; 12th World AIDS Conference; Geneva. June 1998;

29. Zheng X, Wang Z, Xu J, et al. The epidemiological study of HIV infection among paid blood donors in one county of China. Chin J Epidemiol 2000a;21:253-255.

30. Yan J, Zheng X, Zhang X, et al. The survey of prevalence of HIV infection among paid blood donors in one county in China. Chin J Epidemiol 2000;21:10-12.

31. Zheng X. Stop the spread of HIV among drug users and blood donors in China. Chin J Epidemiol 2000b;21:6.

32. Shan H, Wang JX, Ren FR, et al. Blood banking in China. Lancet 2002;360:1770-1775. [PubMed: 12480443]

33. Chen J, Wang Y. On preventive measures in AIDS higher incidence rate area where HIV are transmitted by blood transfusion. Chin J STD/AIDS Prev Cont 2001;7:356-357.

34. Pan, SM. Reality and Absurdity-Underground Sex Industry in China. Qun Yan Publishing House; Beijing: 1999.

35. Schafer, S. Not just another pretty face. Newsweek October 13. 2003. Available at: http://www.aegis.com/news/ads/2003/AD032119/html

36. Qu S, Liu W, Choi K, et al. The potential for rapid sexual transmission of HIV in China: Sexually transmitted diseases and condom failure highly prevalent among female sex workers. AIDS and Behavior 2002;6:267-275.

37. Liao S, Schensul J, Wolffers I. Sex-related health risks and implications for interventions with hospitality women in Hainan, China. AIDS Educ Prev 2003;15:109-121. [PubMed: 12739788]

38. van den Hoek A, Yuliang F, Dukers NH, et al. High prevalence of syphilis and other sexually transmitted diseases among sex workers in China: Potential for fast spread of HIV. AIDS 2001;15:753-759. [PubMed: 11371690]

39. Rogers SJ, Liu Y, Yan TX, et al. Reaching and identifying the STD/HIV risk of sex workers in Beijing. AIDS Educ Prev 2002;14:217-227. [PubMed: 12092924]

40. Lau JT, Tsui HY, Siah PC, Zhang KL. A study on female sex workers in southern China (Shenzhen): HIV-related knowledge, condom use and STD history. AIDS Care 2002;14:219-233. [PubMed: 11940280]

41. Gil VE, Wang MS, Anderson AF, et al. Prostitutes, prostitution and STD/HIV transmission in mainland China. Soc Sci Med 1996;42:141-152. [PubMed: 8745115]

42. Xu L, Yan Y, Chen L, et al. Epidemiological study of HIV-related behaviors in high-risk population in Fuzhou city. Chin J STD/AIDS Prev Cont 2001;7:220-222.

43. Liu S, Fu J, Su S, et al. A survey on characteristics of sexual behavior among women engaging in clandestine prostitution. Chin J STD/AIDS Prev Cont 2001;7:294-295.

44. Zhu G, Sun J, Peng Z, et al. Investigation of condom use among commercial sex workers. Chin J STD/AIDS Prev Cont 2003;9:95-97.

45. China CDC. The Report of STDs Epidemic in China in 2003. China CDC N, \& National Sentinel Surveillance Group; Beijing: 2004b.

46. He X, Li L, Liu H, et al. Investigation of HIV infection rate among attendees of STD clinics. Chin J STD/AIDS Prev Cont 1997;3:153-154.

47. Wang J, Jiang B, Siegal H, et al. Level of AIDS and HIV knowledge and sexual practices among sexually transmitted disease patients in China. Sex Transm Dis 2001a;28:171-175. [PubMed: 11289200]

48. Wang J, Jiang B, Siegal H, et al. Sexual behavior and condom use among patients with sexually transmitted diseases in Jinan, China. Am J Public Health 2001b;91:650-651. [PubMed: 11291385] 
49. Choi KH, Zheng X, Qu S, et al. HIV risk among patients attending sexually transmitted disease clinics in China. AIDS and Behavior 2000;4:111-119.

50. Liu H, Detels R, Ma E, et al. Sexual activities of patients with STDs in the interval between noticing symptoms and presenting for treatment. AIDS Patient Care STDS 2003;17:453-459. [PubMed: 14588083]

51. Liu H, Detels R, Li X, et al. Stigma, delayed treatment, and spousal notification among male patients with sexually transmitted disease in China. Sex Transm Dis 2002;29:335-343. [PubMed: 12035023]

52. Characteristics of Chinese Rural Migrants: 2000. CNBS News Release. China National Bureau of Statistics (CNBS); Beijing: 2001.

53. Shen J, Huang Y. The working and living space of the 'floating population' in China. Asia Pacific Viewpoint 2003;44:51-62.

54. Thomas J. HIV/AIDS in China: migrant population, drug injection responsible for increased transmission. AIDS Link 1998;49:12-14. [PubMed: 12293301]

55. Wang F, Zuo X, Ruan D. Rural migrants in Shanghai: Living under the shadow of socialism. The International Migration Review 2002;36:520-545.

56. Zheng Z, Zhou Y, Zheng L, et al. Sexual behavior and contraceptive use among unmarried, young women migrant workers in five cities in China. Reprod Health Matters 2001;9:118-127. [PubMed: 11468827]

57. Yang Q, Guo W. Occupational attainments of rural to urban temporary economic migrants in China, 1985-1990. The International Migration Review 1996;30:771-787.

58. Xu, C.; Wu, Z.; Zhang, Y. A study on HIV prevalence among rural to urban migrants; Symposium on AIDS Prevention and Control in China; Beijing. 1998; p. 23-24.

59. Sun B. Survey on STD infection among 5892 return hometown farm workers in Jiangyan city, Jiangsu province. Chin J STD/AIDS Prev Cont 1997;3:99-100.

60. Mao Q, Sun B. Survey on STD infection among 983 temporary urban residences. Chin J STD/AIDS Prev Cont 1999;5:14.

61. Li X, Stanton B, Fang X, et al. HIV/STD risk behaviors and perceptions among rural-to-urban migrants in China. AIDS Educ Prev 2004;16:538-556. [PubMed: 15585430]

62. Anderson AF, Qingsi Z, Hua X, Jianfeng B. China's floating population and the potential for HIV transmission: A social-behavioural perspective. AIDS Care 2003;15:177-185. [PubMed: 12856339]

63. Detels R, Wu Z, Rotheram MJ, et al. Sexually transmitted disease prevalence and characteristics of market vendors in eastern China. Sex Transm Dis 2003;30:803-808. [PubMed: 14603085]

64. Liu H, Xie J, Yu W, et al. A study of sexual behavior among rural residents of China. J Acquir Immun Defic Syndr Hum Retrovirol 1998;19:80-88.

65. Wang SM, Gao MY. Employment and contextual impact of safe and unsafe sexual practices for STI and HIV: The situation in China. Int J STD AIDS 2000;11:536-544. [PubMed: 10990339]

66. Parish WL, Laumann EO, Cohen MS, et al. Population-based study of chlamydial infection in China: A hidden epidemic. JAMA 2003;289:1265-1273. [PubMed: 12633188]

67. Liu Z, Yan J, Wu X, Zheng X. A survey on knowledge, attitude and behaviors related to AIDS among the Chinese urban women. Chin J STD/AIDS Prev Cont 2003;9:12-15.

68. Beyrer C. Hidden epidemic of sexually transmitted diseases in China: Crisis and opportunity. JAMA 2003;289:1303-1305. [PubMed: 12633193]

69. Saphonn V, Sopheab H, Sun LP, et al. Current HIV/AIDS/STI epidemic: Intervention programs in Cambodia, 1993-2003. AIDS Educ Prev 2004;16:64-77. [PubMed: 15262566]

70. Phoolcharoen W, Ungchusak K, Sittitrai W, Brown T. Thailand: Lessons from a strong national response to HIV/AIDS. AIDS 1998;12(suppl B):S123-S135. [PubMed: 9679638] 


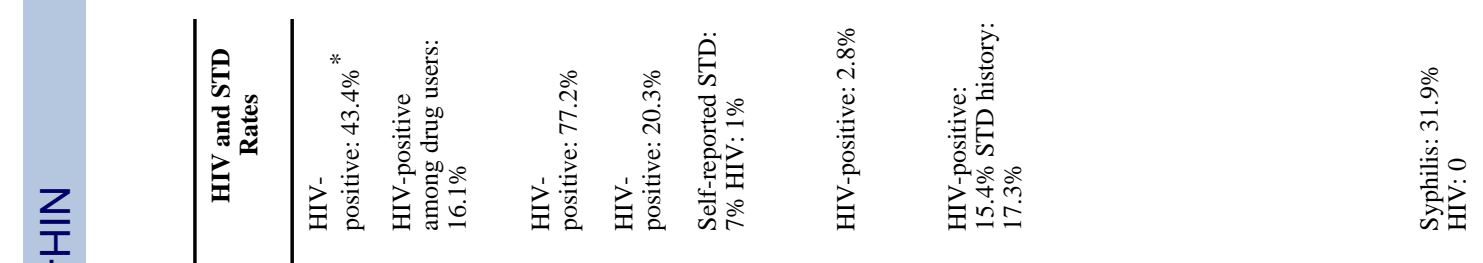

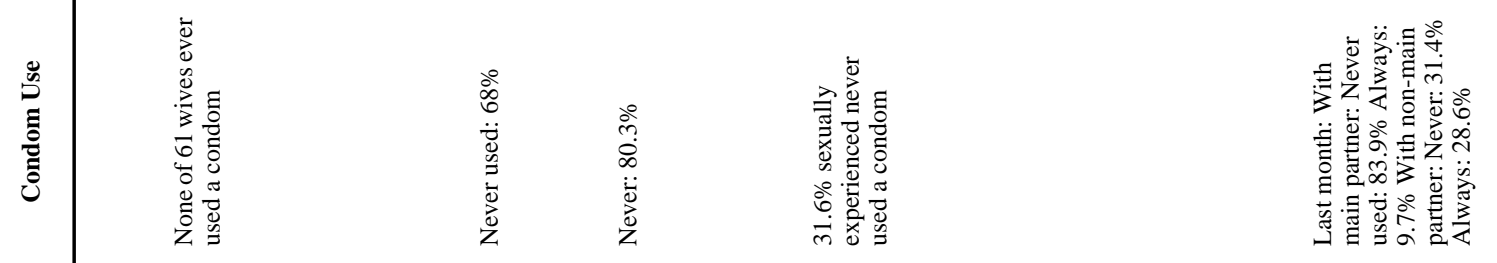

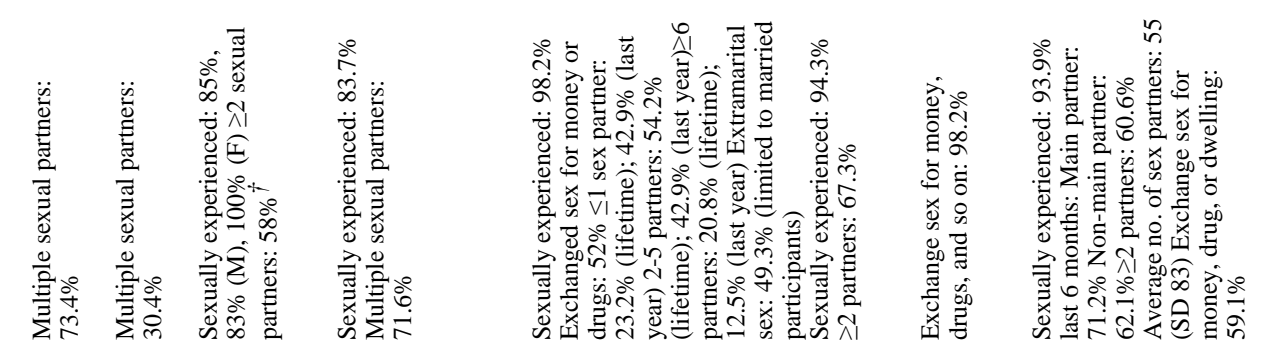

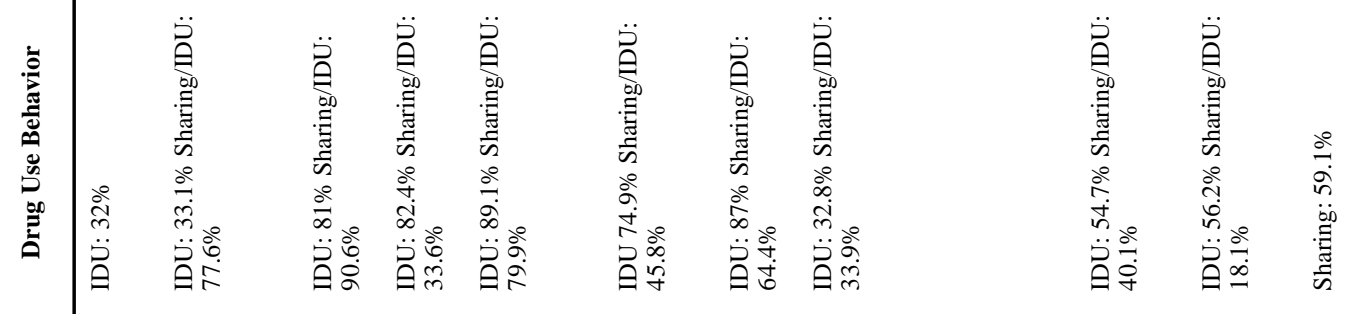

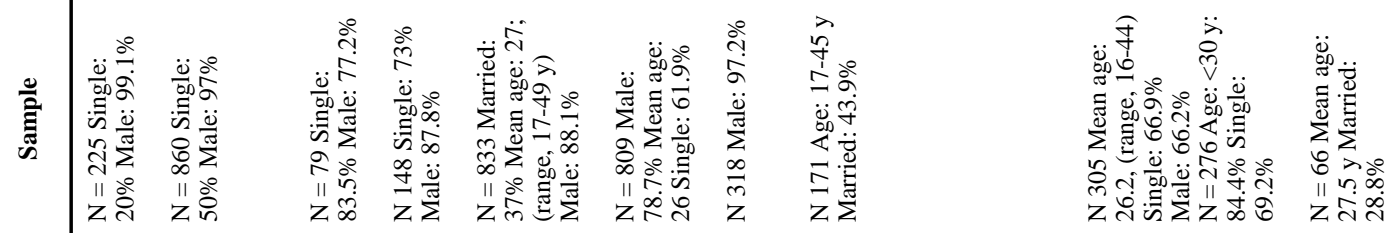

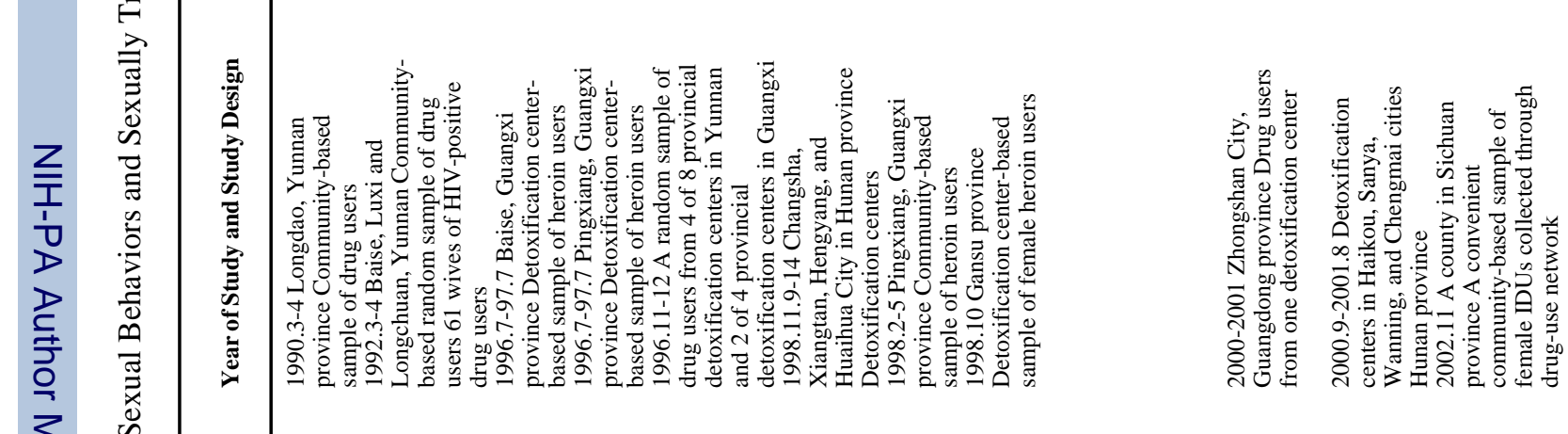

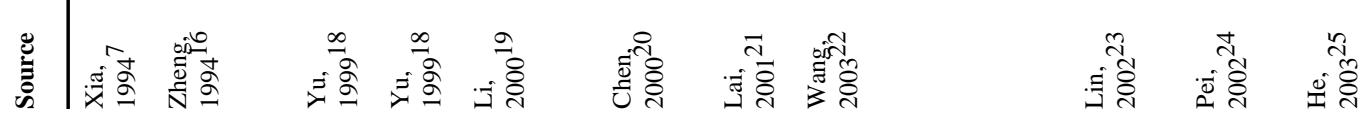




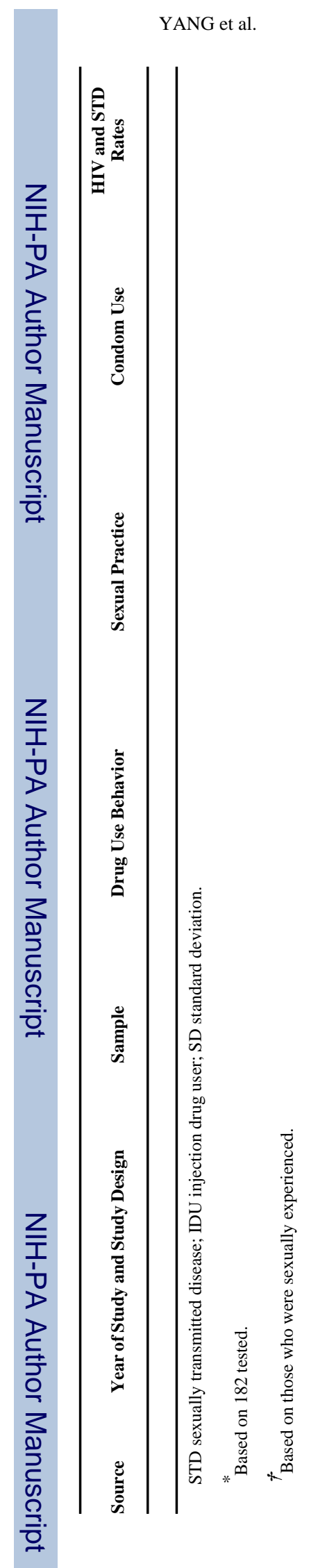

Page 13 

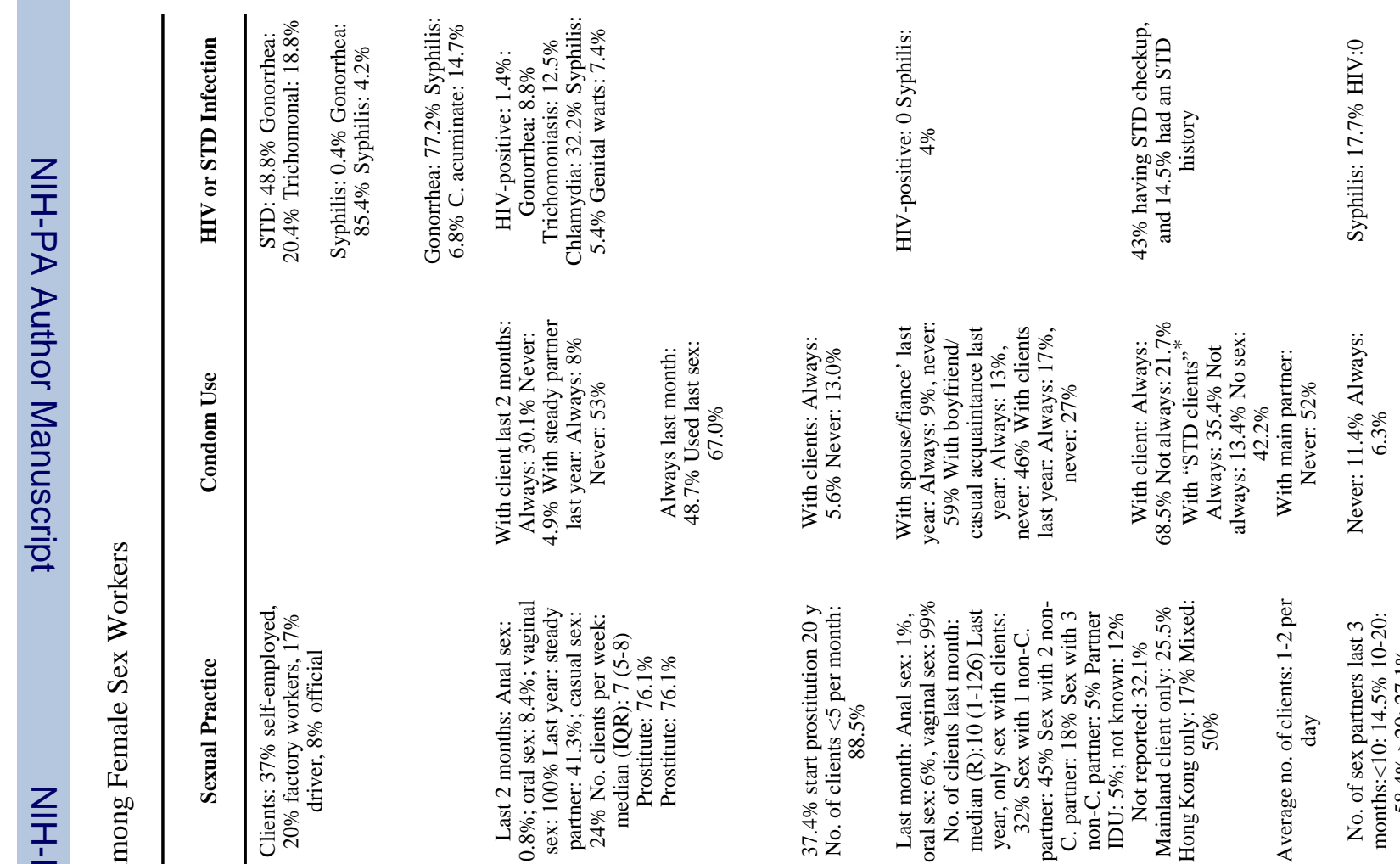

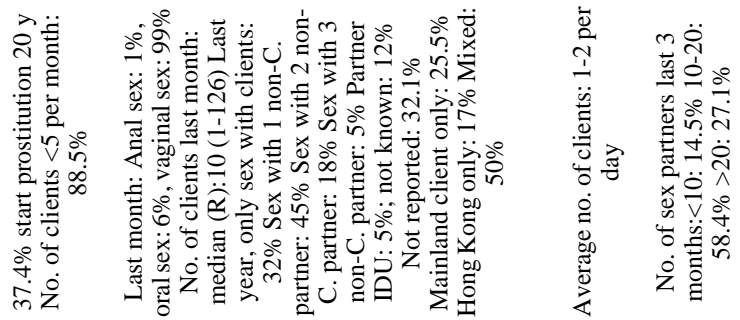

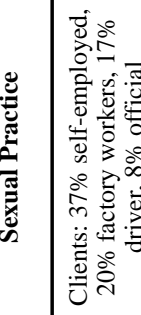

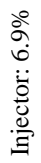

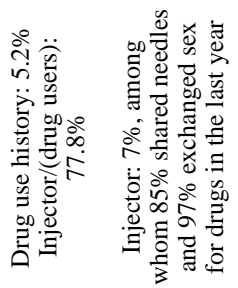

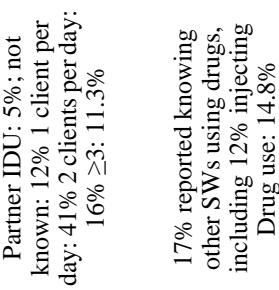

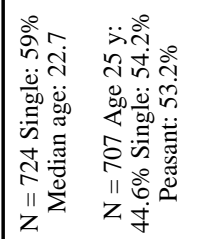

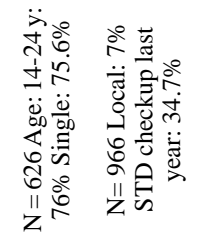

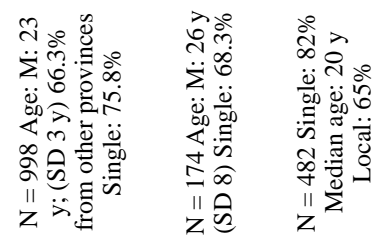

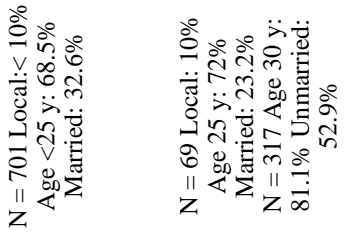

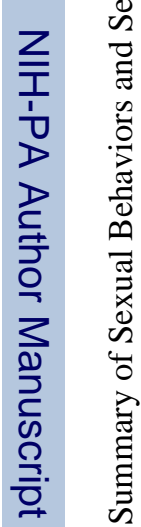

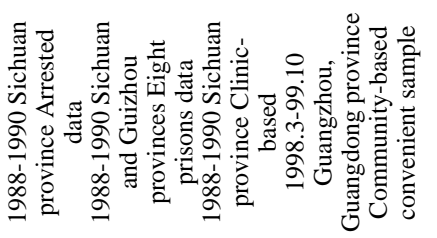

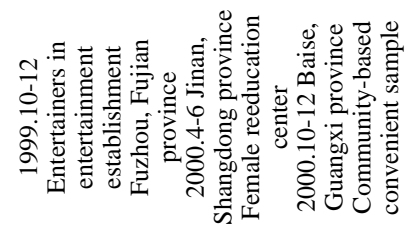

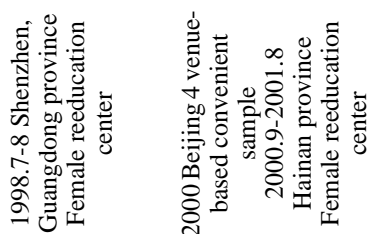

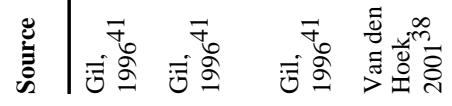

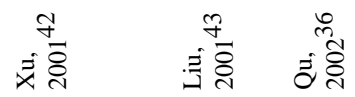

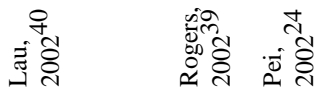




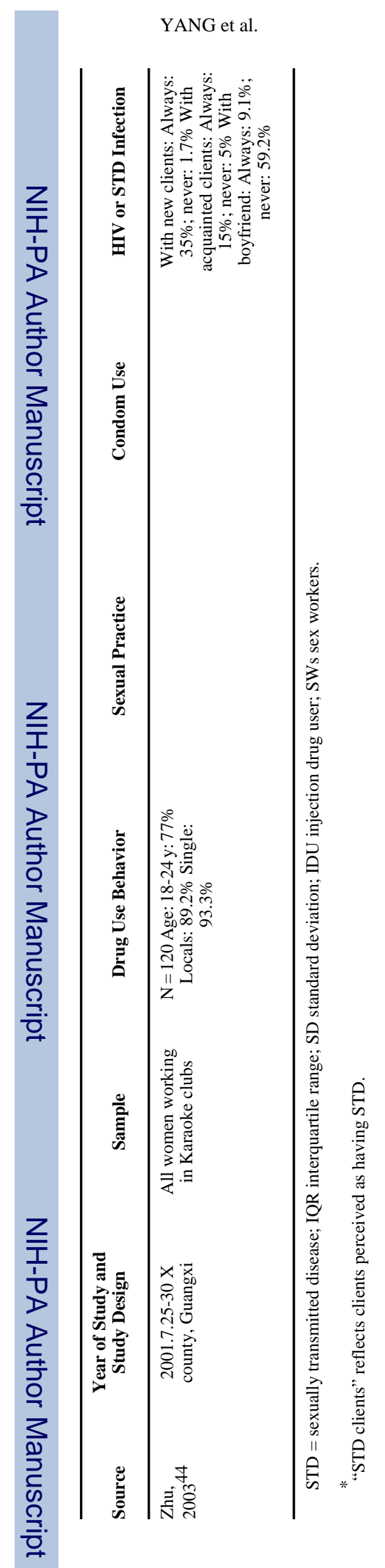

Sex Transm Dis. Author manuscript; available in PMC 2007 February 5. 


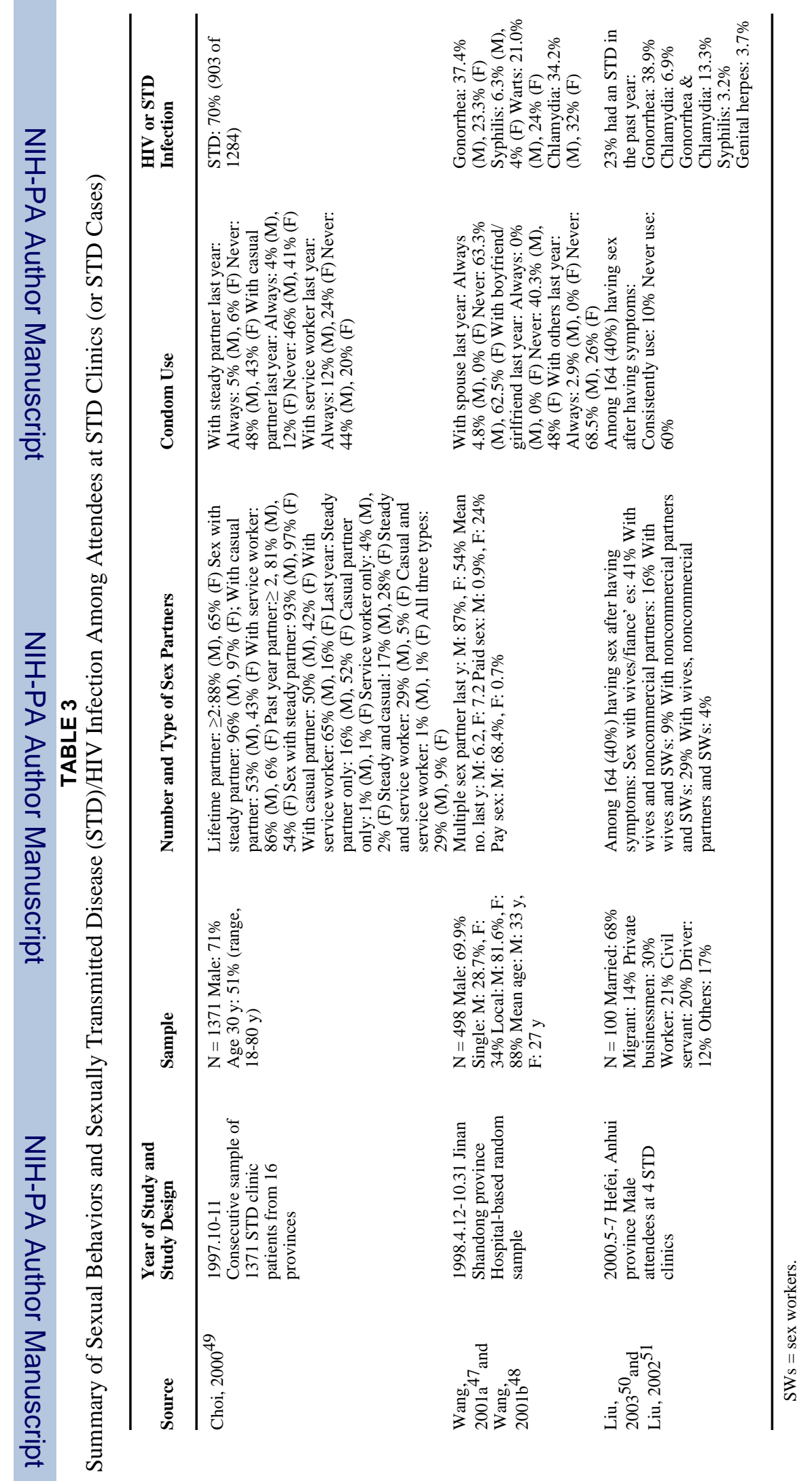




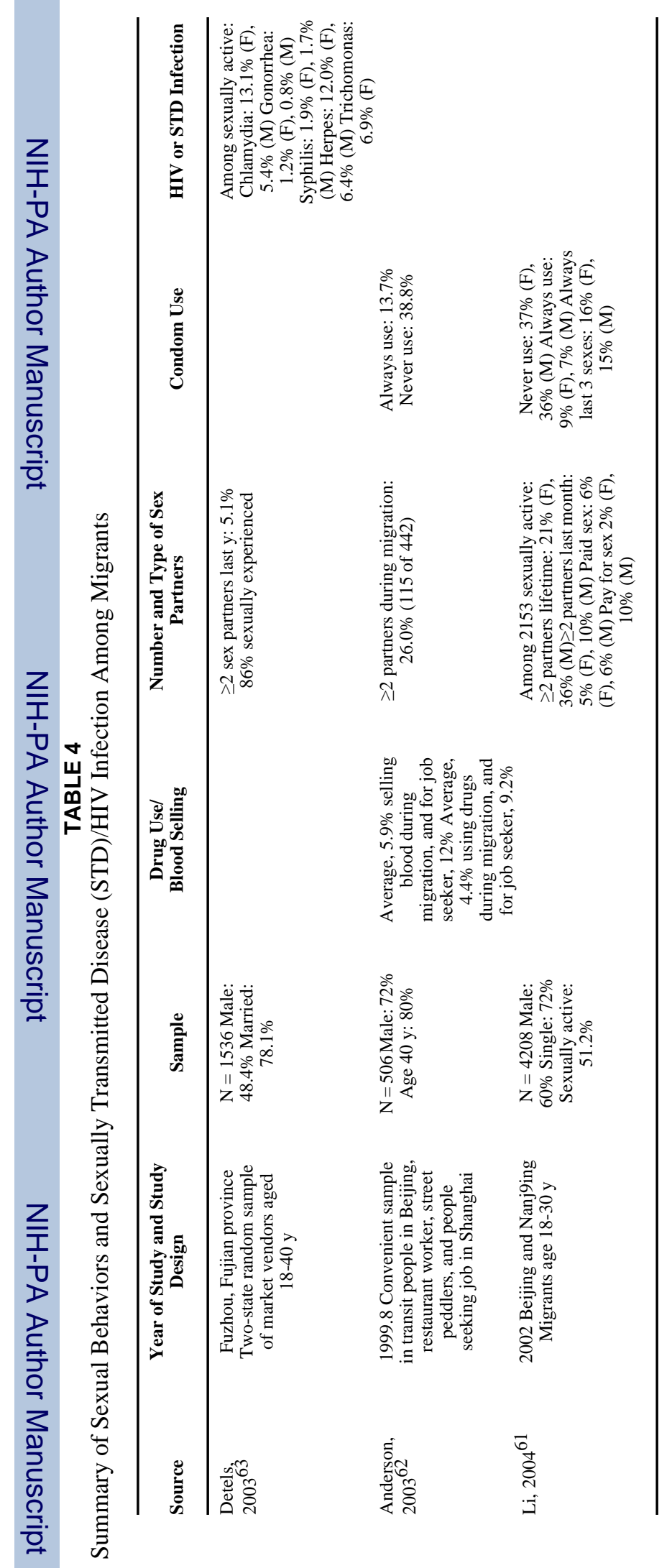

Sex Transm Dis. Author manuscript; available in PMC 2007 February 5. 


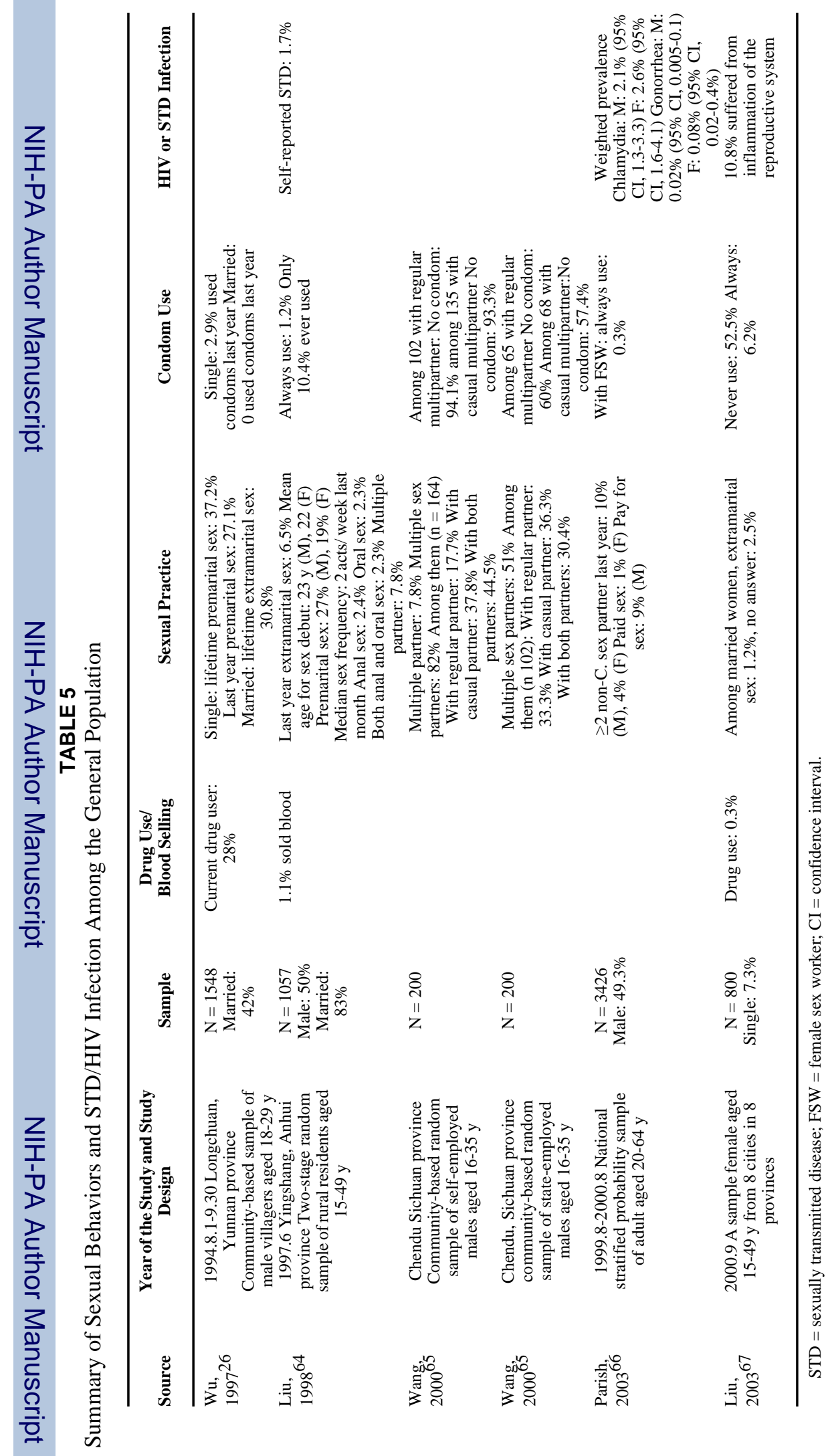

